\title{
GAS-POLARIZATION IN LEAD ACCUMULATORS
}

\author{
BY C. J. REED
}

Nernst and Dolezalek have published in Zeitschrift für Elektrochemie of May IO, I goo, a discussion of the "GasPolarization of Lead Accumulators". The conclusions arrived at and the interpretations given to certain experimental results do not seem to be tenable. Some of the statements as to experimental facts also appear on investigation to be not well founded. The preliminary statement is made that the electrolysis of dilute sulphuric acid between lead electrodes does not take place with an electromotive force of less than about two wolts; that the products of electrolysis are not hydrogen and oxygen, but lead and lead peroxide; that gras is generated only when the dectromotize force is increased to about 2.3 i'olts.

$\mathrm{O}_{11}$ the strength of these statements alone it is assumed that the formation of lead and lead peroxide from lead sulphate in a lead accumulator takes place at an electromotio' force less than that required to decompose atater, and that, therefore, there results from elcctrolysis, not the reaction absorbing the least 'nergy, but a reaction absorbing considcrably more energy', namely, the formation of lead and load peroxide, instead of hydrogen and oxygen.

Influenced by these assumptions and the conclusions deduced therefrom, the authors have built up an explanation of a supposed anomaly, which really does not exist. The specific problem proposed by the authors for explanation was, why can a lead accumulator with an aqueous electrolyte and an electromithe force exceding ta' wolts crist, since the electrolyte is decomposed rapidly between platimum plates when the electromotive force reaches $\mathrm{r} . \mathrm{T}$ a'olts! 
The rational solution of this question and the rational acconnting for all of the changes in energy and matter may or may not be difficult when the facts have been correctly ascertained and stated. But the theory adrocated in the paper referred to above is somewhat startling. This theory is that the liberation of hydrogen from a given combination and condition does not require the absorption of a fixed quantity of energy, but a variable quantity, the value of which depends upon the occlucling or absorbing capacity of an adjacent body - not upon the energy evolved or absorbed in occlusion, but merely upon the relative mass or volume of hydrogen that a unit of the adjacent body is capable of occluding. They assume that greater energy is required to liberate hydrogen in contact with lead than is required to liberate it in contact with platinum, simply because the platinum has a greater occluding capacity for hydrogen than for lead.

The results which wonld follow from such a theory; if it could be established, are so momentons, and the sponsors who stand for the theory are of stch eminent authority; that I shall consider it unnecessary to apologize for going rather minutely into the details of the experimental facts and arguments, which seem to entirely refute it.

In order that there may be no misunderstanding, it will be necessary to quote at some length the statements of Nernst and Dolezalek. They say :

"The explanation of this abnormal property of lead, through which, evidently, is furnished the possibility of making an accumulator of two volts, may easily be derived from the recently announced theory concerning the generation of hydrogen in contact with metals, which was demonstrated by the experiments of Caspari.

"According to this [theory]' there is to be added to the

1 Reference is cited by the authors to Caspari's paper "Ueber Wasserstofientwicklung", Ztschr. phys. Chem. 3o, H. I., S9. But an examination of the paper reveals the fact that the proof referred to is only the supposition of Caspari. and is not at all warranted by the experiments he describes. He 
minimum electromotive force of decomposition of an electrolyte (free formation energy) a term which takes into consideration a specific property of the electrode material, and which, as the experiments make probable, is inversely proportional to the absorbing capacity of the electrode metal for hydrogen. It seems, therefore, that the work, which is required for the formation of hydrogen bubbles on a metallic surface, decreases exceedingly with the [increasing] occluding capacity".

From this assumption the authors have concluded that, since the occluding capacity of lead for hydrogen is very small in comparison with the occluding capacity of platinum, the energy required to form hydrogen "bubbles" on a lead plate is, therefore, greater than that required with a platinum plate and greater than the formation energy of the decomposed compound. In other words, it is assumed that the quantity of energy required to electrolytically separate hydrogen gas from a specific combination and condition is not constant, but depends upon a phrsical property of an adjacent body. They also assume, incidentally, that the liberation of lydrogen with lead electrodes is a secondary reaction, the decomposition of $\mathrm{PbSO}_{+}$being the primary, that is, the electrochemical reaction.

Against these assertions and assumptions I wish to place the following statements, which are held to be capable of experimental demonstration:

I. Hydrogen gas is evolved electrolytically in unlimited quantities from dilute sulfuric acid with electrodes of pure metallic lead when the electromotive force is less than 0.5 volt.

2. The electromotive force required to maintain a steady. current between electrodes of metallic lead is less than 0.01 volt.

3. This occurs withont the agency or presence of lead sulphate in the solution or on the cathode.

4. The electromotive force required to charge an accunnula-

entirely ignored the electrochemical reactions taking place and the electromotive forces due to the corresponding energy changes. His inferences, therefore, cannot be called proof. 
tor is in no way dependent upon or related to the evolution of hydrogen or oxygen on a lead electrode, nor is it dependent upon the occluding capacity of lead.

The experimental demonstration of the first two of these propositions is of the utmost importance, as it leaves the entire theory of Nernst and Dolezalek, not only without facts to stand on, but without any object or anomaly to explain.

In order to prove that with lead electrodes lydrogen is evolved with less than 0.5 volt, it is only necessary to provide for a continuation of the reaction between lead electrodes long enongh to study the reaction and to measure the electromotive force. This requires a rather large anode surface, becanse the electrochemical action rapidly changes the lead anode into an anode of lead sulphate. This change results in an entirely different electrochemical reaction as soon as the entire available or exposed surface of the lead anode has been converted into sulphate. A large mass of small, bright lead wire may be used satisfactorily as an anode and a small, bright lead wire as a cathode.

The anount of lead sulphate formed on the surface of the anode by a given current is, according to Faraday's law, proportional to the time the reaction continues. As the lead sulphate must cover the entire exposed surface of the anode to a certain depth before the reaction is interrupted or superseded by a different reaction, we have, evidently, only to provide a sufficiently. large area of anode surface, in order to continue the reaction at a fixed rate for any desired period of time.

The evolution of hydrogen may be observed for a few seconds in considerable volume at 0.5 volt with an anode of lead having an area of only twenty-five square centimeters, if the lead cathode is reduced to a small sharp point. The most convenient and obvious method, however, of prolonging the reaction is to use as an anode, lead in a state of molecular or very minute dirision, subdirided chemically or electrolytically, such as is readily obtained in a charged negative accumulator plate, or in an electrolytically deposited "lead tree". By using such 
an anode and a clean strip of sheet lead as a cathode, we are enabled to prolong the demonstration as long as there remains any arailable metallic lead in the anode, or, in other words, mint the accumulator plate is "sulphated" or discharged.

In all of the varions experimental investigations referred to in the paper under consideration no attempt appears to have been made to really ascertain and to consider the chemical changes successively produced by the current, nor the energy changes, which must necessarily accompany those chemical changes. For example, electrodes of lead were interchanged with electrodes of lead sulphate or of platinum withont considering that such a change would entirely alter the chemical reactions. One important consideration, which was entirely ignored, is the fact that an electric current passing between lead electrodes in pure, dilute sulphuric acid can produce at the cathode, hydrogen only, and at the anode, lead sulphate only. Consequently, the experiments of these investigators were not conducted under conditions which would enable then to detect these facts. If copper electrodes had been substituted for the lead electrodes, they would have noticed at once that the only products are copper sulphate at the anode and hydrogen at the cathode. With lead electrodes the reaction is similar, except that lead stlphate, instead of copper sulphate, is necessarily formed at the anode. Of course, the lead sulphate is much more insoluble than the copper sulphate and, in a very thin layer, is less evident to the muacled eye on account of being uncolored, but these well-known facts afford no ground for supposing that the lead sulphate is not formed under those conditions. On the contrary, we have abundant proof of the formation of lead sulphate under these identical conditions in the discharge of an ordinary lead accumnlator. The available or exposed metallic lead (in spongy form) of the negative plate of an accumulator acts as an anode during discharge and is thereby conrerted directly, without the formation of any gas, into lead sulphate. This was proved many years ago by Gladstone and Tribe, and has been corrohorated by all subsequent investigations. 
When all of the exposed metallic lead of such an accumnlator plate has been converted into lead sulphate, there is no longer any contact between the lead and the electrolyte. Metallic lead is no longer the electrode. The conversion of the lead electrode into lead sulphate has produced a new apparatus, niew conditions, and a new reaction must occur, if the current is continued. An anode of lead sulphate has been substituted for an anode of lead, the mass of lead which remains nnsulphated acting only as a conductor and helping to complete the circuit. Any electrochenical action which now takes place at the anode can affect only the lead sulphate or the electrolyte, the metallic lead having been entirely removed from the sphere of action. This change in the anode from lead to lead sulphate is very rapid and is completed in a fraction of a second with a small current, when the exposed surface is small, owing to the insolubility of the lead sulphate, which limits the reaction to a very thin, almost molecular external layer. But when the lead is minutely powdered, so as to expose to the electrolyte a large proportion of its mass, as in the ordinary accumulator plate, the time and current required to complete the change are proportionately greater.

If, after this change has been completed, the current be continned in the same direction, any one of sereral electrochenlical reactions may occur, including the following:

I. The lead sulphate at the anode may be converted by oxidation into lead peroxide, $\mathrm{PbO}{ }_{2}$, or into lead persulphate, $\mathrm{Pb}\left(\mathrm{SO}_{4}\right)_{2}$.

2. After the anode has been converted wholly or partly into lead peroxide the electrolyte may be decomposed with the formation of any of several oxidation products, including oxygen, hydrogen peroxide, ozone, and persulphuric acid.

For each of these chemical changes there is an evolution or absorption of a definite quantity of clemical energy. The chenical energy of an electrochemical change is always added to or taken from the electrical energy of the circuit and either increases or dininishes the electromotive force between the electrodes, depending upon whether the chemical energy of the 
reaction is exothermic or endothermic. An attempt, therefore, to determine the electromotive force required to liberate hyclrogren by measuring the potential difference between a lead cathode and an anode which changes from metallic lead, firstly to lead sulphate and then to lead peroxide, without considering the energy of these changes or determining which change is taking place at the time of the measurement, would appear to be the height of absurdity. Neither concentrations, osmotic pressures, nor mathematical formuluce can assist in snch an undertaking.

It is evident from their restlts, as well as their statements, that no measurements were made by Nernst and Dolezalek or by Caspari of the electromotive force required to liberate hydrogen with lead elcotrodes, that no measurements were commenced until after the anode had ceased to be an anode of lead. Caspari states, for example, that he waited until the current became constant at a definite ralue before making his measurements, that is, n11til his anode was thoronghly converted into lead peroxide.

The fact that in their experiments the electromotive force required to evolve hydrogen was low during a brief initial period seems to have been noticed, but purposely ignored by all of the investigators, as thongh it were too insignificant a matter to be worthy of any serious consideration. let it was during this brief period only that the electrodes consisted of lead and it was the electromotive force between electrodes of lead that formed the subject of their investigations.

The electrochemical reaction between electrodes of metallic lead, which results in the formation of lead stuphate, is a reaction evolving very great energy (more than that required to liberate hydrogen), but all of the reactions occurring after the anode lias been converted into lead sulphate or lead peroxide, absorb energy. Hence, the electromotive force required to produce a current will be different in the different cases, whether any hydrogen is liberated or not. The energy required to liberate hydrogen from a given chemical combination under given 
conditions evidently corresponds to a fixed electrochemical electromotive force. But the electromotive force found experimentally between two electrodes, at one of which hydrogen is evolved electrolytically, is merely the sum of this and all other electromotive forces included in the circuit between the two electrodes. This observed electromotive force between the electrodes is not, therefore, a measure of the electromotive force required to liberate hydrogen. No method has yet been fonnd of eliminating experimentally the electromotive force at the other terminal of the electrolyte. The electromotive force between an electrolyte and a single electrode has never been measured and we have no positive experimental evidence that any such electromotive force exists. The use of a so-called "normal electrode" does not help us in the least. We are still measuring only the electromotive force between two electrodes.

The only known sources of electromotive force (positive or negative) between two electrodes emersed in an electrolyte are the electrochemical, the Jonle, the Thomson (Kelvin), and the Peltier effects. The electromotive forces caused by the Joule, Thomson, and Peltier effects are due to energy introduced into or eliminated from the circuit in the form of heat. The Jonle effect acts only in opposing an equal or greater electromotive force.

When the temperature of the system is maintained constant and uniform, the intensities of these thermo-electromotive forces are proportional to the strength of the electric current. They are, therefore, entirely eliminated when the temperature is constant and uniform and the current is zero. The electromotive force caused by the electrochemical effect is, however, not dependent upon the strength of the electric current, but depends only upon the chenical energy of one univalent electrochemical equivalent of the reacting substances. It follows, therefore, that, when the temperature of an electrochenical system is uniform and constant and the current zero, the measured electromotive force is that due solely to the electrochemical effect.

In the electrolysis of dilute sulpluric acid between elec- 
trodes of lead the electrochemical reaction restlts in the formaof lead sulphate at the anode and hydrogen at the cathode, the complete electrochemical change being represented by the equation,

$$
\mathrm{Pb}=\mathrm{H}_{2} \mathrm{SO}_{4} \mathrm{Aq}=\mathrm{PbSO}_{4}+2 \mathrm{H}+\mathrm{Aq} \ldots \ldots \cdot \ldots(\mathrm{r})
$$

The energy evolved by this reaction is, expressed as the equivalent in the form of heat, $215,700-210,100=5,600$ (Berthelot) calories. The chemical affinity tending to cause this change to take place at either electrode is equivalent to an electromotive force of $\frac{5,600}{2 \times 23,240}=0.12$ volt. As this affinity exists at each electrode, the electrochemical electromotive forces balance and can cause no current in either direction. The system cannot of itself produce an electric current through an external circuit. If, however, the slightest electromotive force be impressed upon the system from an external source in either direction throngh a closed circuit, the current can flow, produ. cing lead sulphate at the anode and hydrogen at the cathode.

In the experiments performed by the writer, 0.38 volt was the lowest external electromotive force, with which an evolution of hydrogen was observed, but it was found that an electromotive force of 0.0 r volt was sufficient to maintain a steady current. The source of the electromotive force used was a separately ex. cited dynamo.

When the anode has been converted into lead sulphate and the cathode remains metallic lead, the next reaction forms lead peroxide, hydrogen, and sulphuric acid as follows:

$$
\mathrm{PbSO}_{4}+\mathrm{H}_{2} \mathrm{SO}_{4} \mathrm{Aq}=2 \mathrm{H}-\mathrm{PbO}_{2}-{ }_{2} \mathrm{SO}_{3} \mathrm{Aq} \ldots . . \text { (2). }
$$

This reaction absorbs an electromotive force equivalent to

$$
\frac{215,700+210,100}{2 \times 23,240} \frac{-(6,400+2 \times 141,100)}{2}=1,73 \text { volts. }
$$

Ozone, $\mathrm{O}_{3}$, will also be simultaneously formed by the independent electrolytic decomposition of the electrolyte between the $\mathrm{PbO}_{2}$ anode thus formed and the lead cathode according to the equation,

$$
{ }_{3} \mathrm{H}_{2} \mathrm{SO}_{4} \mathrm{Aq}:=6 \mathrm{H}+\mathrm{O}_{3} \div{ }_{3} \mathrm{SO}_{3} \mathrm{Aq} \cdots \cdots \cdots(3) .
$$


The electromotive force absorbed is equivalent to

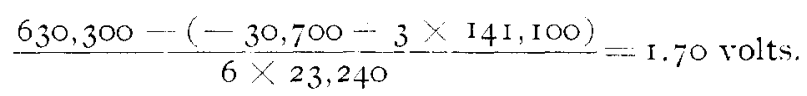

As the electromotive force required to form ozone is 0.03 volt less than that required to form lead peroxide, there will always be some ozone formed as soon as there is any lead peroxide to act as an anode, that is, as soon as any current has passed. In practice it is found that the lead peroxide and the ozone always appear simultaneously when the operation is conducted at ordinary temperatures.

With an anode of lead peroxide and a cathode of metallic lead we may have the formation of either lead persulphate, $\mathrm{Pb}\left(\mathrm{SO}_{4}\right)_{2}$, hydrogen peroxide, $\mathrm{H}_{2} \mathrm{O}_{2}$, or persulphuric acid, $\mathrm{HSO}_{4}$, at the anode and hydrogen at the cathode. The formation of the lead persulphate is represented by the equation,

$$
\left.\mathrm{PbSO}_{4}+\mathrm{H}_{2} \mathrm{SO}_{4} \mathrm{Aq} \cdots \mathrm{Pb}\left(\mathrm{SO}_{4}\right)_{2}-{ }_{2} \mathrm{H}-\mathrm{Aq} \cdots \ldots .44\right) .
$$

The formation energy of $\mathrm{Pb}\left(\mathrm{SO}_{4}\right)_{2}$ does not appear to have been published.

The formation of hydrogen peroxide with an anode of lead peroxide and a cathode of metallic lead is according to the equation,

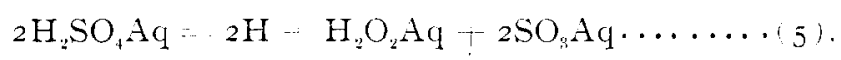

This absorbs on electromotive force equivalent to

$$
\frac{\left.2 \times 210,100-\frac{47,300-1}{2} \times 2 \times 141,100\right)}{23,240}+1.95 \text { volts. }
$$

The formation of persulphuric acid with an anode of lead peroxide and a cathode of metallic lead is represented by the equation,

$$
2 \mathrm{H}_{2} \mathrm{SO}_{4} \mathrm{Aq} \cdot 2 \mathrm{HSO}_{4} \mathrm{Aq} \cdot{ }_{2} \mathrm{H} \ldots \ldots \ldots \ldots(6) \text {. }
$$

The absorption is

$$
\frac{2 \times 210,100-2 \times 158,200}{2 \times 23,240}-2.23 \text { rolts. }
$$

Reactions (I), (2), (3), (5), and (6) are known to occur. 
while (4) is known not to occur to any appreciable extent, since lead persulphate is very soluble and its formation would carry the lead into solution, where it would be precipitated as lead sulphate, leaving persulphuric acid in solution.

In all of the cases cited above the cathode is of metallic lead. If, instead of metallic lead, we use a cathode of lead sulphate and an anode of lead sulphate or lead peroxide, such as we have in the charging of a discharged accumulator, no current can pass without the reduction of the lead sulphate of the cathode to metallic lead and the oxidation of the lead sulphate of the anode to lead peroxide, the reaction being,

$$
\mathrm{Aq}+2 \mathrm{PbSO}_{+}=\mathrm{PbO}_{2}-\mathrm{Pb}+2 \mathrm{SO}_{3} \mathrm{Aq} \cdots \cdots \cdots(7)
$$

The absorption is

$$
\frac{2 \times 215,700-(63,400-2 \times 141,100)}{2 \times .23,240}=1.845 \text { volts. }
$$

With the formation of lead and persulphuric acid from a cathode of lead sulphate and an anode of lead peroxide we have

$$
\mathrm{H}_{2} \mathrm{SO}_{4} \mathrm{Aq}+\mathrm{PbSO}_{4}=\mathrm{Pb}+{ }_{2} \mathrm{HSO}_{4} \mathrm{Aq} \cdots \ldots . .(8) .
$$

The absorption is

$$
215,700-210,100-2 \times 158,200-2.36 \text { volts. }
$$

In the reaction forming ozone and metallic lead from a cathode of lead sulphate and an anode of lead peroxide we have

$$
\mathrm{Aq}+{ }_{3} \mathrm{PbSO}_{4}={ }_{3} \mathrm{~Pb}-{ }_{3} \mathrm{SO}_{3} \mathrm{Aq}+\mathrm{O}_{3} \ldots \ldots \ldots(9) \text {. }
$$

The absorption is

$$
\frac{3 \times 215,700-(3 \times 141,100-30,700)}{6 \times 23,240}=1.82 \text { volts. }
$$

In the reaction forming hydrogen peroxide and metallic lead, we have

$$
\mathrm{PbSO}_{4}-\mathrm{H}_{2} \mathrm{SO}_{4} \mathrm{Aq}=\mathrm{Pb} \rightarrow \mathrm{H}_{2} \mathrm{O}_{2} \mathrm{Aq}+2 \mathrm{SO}_{3} \mathrm{Aq} \cdots . . \text { (го). }
$$

The absorption is

$$
\frac{215,700+210,100-(47,300+2 \times 14 \mathrm{I}, 100)}{2 \times 23,240}=2.07 \text { volts. }
$$


In the above reactions it has been assumed that the sulphuric acid liberated from lead sulphate is always liberated as $\mathrm{SO}_{2} \mathrm{Aq}$, that is, as zery dilute acid. In ordinary practice with lead accumulators this assumption is not correct, as the acid used in the accumulator is not very dilute and the dilution of the electrolytically liberated acid cannot exceed the dilution of the acid into which it is liberated. The acid set free will, as a matter of fact, always be considerably stronger than the solution constituting the electrolyte, particularly in the interior of a spongy electrode. A correction must, therefore, be added to the above results, which is the equivalent of the additional energy required to liberate the stronger acid. The total energy required to concentrate the most dilute acid to its maximum density

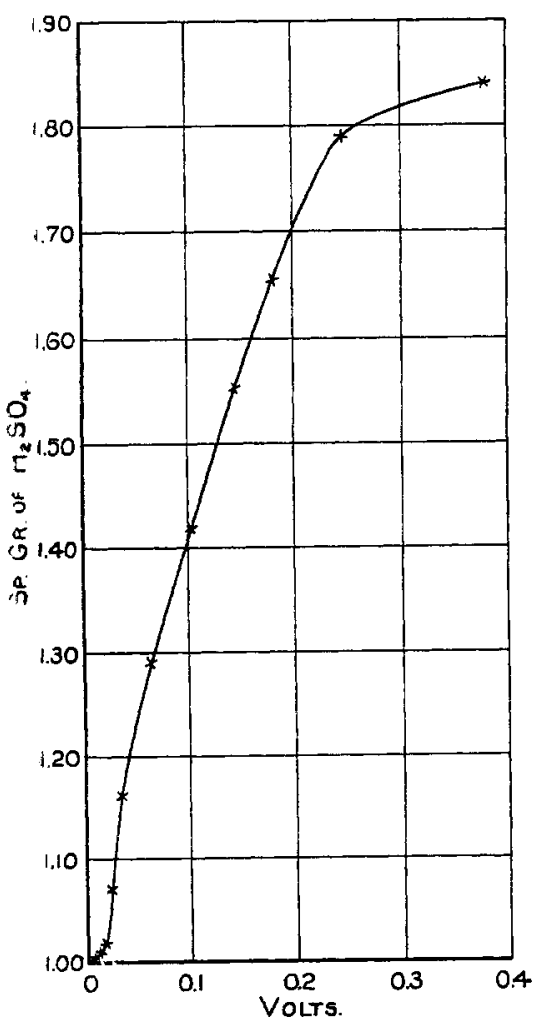

(specific gravity of 1.842 ) is I 7,850 calories per equivalent (bivalent), corresponding to an electromotive force of $\frac{17,850}{2 \times 2,3,240}$ $=0.38$ volt. The necessary correction cannot, therefore, exceed this value. For any particular density of acid the corresponding dilution heat expressed in calories and the equivalent correction expressed in rolts may be taken directly from the accompanying curve. The proper correction corresponding to the density of the acid used must be added once if the reaction liberates free acid at only one electrode, as in equation (2), and nunst be added twice when the acid is liberated at both electrodes, as in equation $(7)$. 
Assuning that in an accumulator the density of the electrolyte is I.2O, the strength of the acid liberated will be at least I. 20 and will probably be at least I. 3 o or I. 35 at the point where it is liberated, that is, in the pores of the spongy electrodes. The correction corresponding to acid of this density is found from the curve to be 0.08 volt.

Applying this correction to the above reactions, we obtain in equation

\begin{tabular}{|c|c|c|c|c|c|}
\hline (2) & 1.73 & $\cdots$ & & 0.08 & I. $8 \mathrm{I}$ \\
\hline (3) & 1.70 & $i$ & & $0.08==$ & I. 78 \\
\hline (5) & 1.95 & $\therefore$ & & $0.08 \cdots$ & 2.03 \\
\hline$(7)$ & 1,845 & -. 2 & $2 x$ & $0.08=$ & 2.00 \\
\hline (8) & 2.36 & $\because$ & & $0.08==$ & 2.44 \\
\hline (9) & 1.82 & 2 & $2 x$ & 0.08 & 1.98 \\
\hline O & 2.07 & $\because \quad 2$ & $2 x$ & 0.08 & 2.23 \\
\hline
\end{tabular}

The formation heats used in these calculations were mostly made at a temperature of about $15^{\circ} \mathrm{C}$, and the electromotive forces are, therefore, correct for an electrochemical system maintained at that temperature when the circuit is open or when the current is very minute. It is scarcely necessary to add that they: are entirely in accord with those universally obtained in practice. The increase in the strength of the acid in the pores of the active material and the consequent formation of persulphuric acid at the end of the charge acconnts satisfactorily for the high electromotive force required.

When the electrodes of an electrochemical system constitute also the electrochemical reagents, as is the case with the leaci sulphate, lead peroxide, and metallic lead of an accumulator, the decomposition tension of the intervening electrolyte is not necessarily a factor in determining the electromotive force between the electrodes. It will usually be a factor if the constituents of the electrolyte are actually set free. But it cannot be a factor if none of the constituents of the electrolyte are liberated by the electrochemical action, because the decomposition cannot then cause the absorption or evolution of the formation energy. The energy required to evolve the actual products formed by electro- 
chemical action at the electrodes is always a measure of the electromotive force necessary to do the work of chemical separation (or combination) resulting in those products. If, for example, there were a dozen electrolytes intervening in series (separated by porous diaphragms) between the electrodes, the passage of the current throngh the series would cause decomposition (interchange of bases and acid radicles) at both terminals of each intervening electrolyte; but, as the constituents of these intermediate electrolytes are not set free, the electromotive force required for such liberation is not imposed upon the circuit. The same is true of a single electrolyte, such as dilute sulphuric acid, intervening between two electrodes, such as lead sulphate, which furnish the liberated products of electrochemical action. In this case the products liberated are lead, lead peroxide, and sulphuric acid, and the electromotive force required for the passage of the current is that which corresponds to the energy required to separate these bodies only, and is in no way dependent upon the electromotive force required to decompose any electrolyte or electrolytes that may intervene.

The chemical changes at the two electrodes occur in series and the current can reach the electrolyte only by passing into and out of the lead strlphate electrodes and decomposing this substance at both places. If the current conld have access to the electrolyte withont passing in series throngh the electrodes and decomposing them (as would be the case with platinum electrodes), the constitnents of the electrolyte would be liberated and the electromotive force required would correspond to the energy of such liberation. But the current must cross the junctions between the electrolyte and the electrodes in series, and when these electrodes are of lead sulphate, they must undergo electrochemical decomposition.

When all available lead sulphate on both electrodes of an accumulator has been converted into the products, lead, lead peroxide, and sulphuric acid, the electrodes can no longer supply the products of electrochemical action and they must be supplied by the electrolyte. Oxygen, hydrogen, ozone, hydrogen perox- 
ide, and pursulphuric acid then appear in quantities corresponding to the total current. But these products can then be liberated only by the passage of the current, and no current can pass without an electronotive force exceeding the connter-electromotive force of the charged accumulator with all of the products that have been formed. We might as well expect a boat to move against the current of a river when its relocity is less than that of the stream.

To prove that the liberation of hydrogen on a lead cathode is not due to the primary reduction of lead sulphate by the current and the secondary chenical action of the reduced lead on the water or acid present, it will be sufficient to show that the hydrogen is liberated in the same manner whether lead sulphate is present or not. This may be shown by electrolyzing with an anode of platinum and a cathode of clean, bright, metallic lead a solution of pure dilute sulpluric acid. Although there is no lead sulphate present, either on the cathode or in the solution, the passage of the current causes an instantaneous evolution of hydrogen as soon as the lead cathode touches the solution, the quantity being limited only by the current. It cannot be supposed that the action of the current at the cathode is to form and then reduce lead sulphate. As there is no other possible source of lead sulphate, there cannot be any present either before or during the passage of the current. Furthermore, an examination of the acid surrounding the cathode immediately afterwards shows no trace of lead sulphate or any other impurities, the acid evaporating without residue, though several hundred cubic centimeters of hydrogen may have been liberated.

This may be accomplished under practically the sane conditions with both electrodes of lead and an electronotive force of 0.5 roit by using an anode of finely divided lead and surrounding the cathode with a porous cup containing the pure acid.

If the liberation of hydrogen is a secondary action, that is, the chemical action of reduced metallic lead on the water or dilute acid, it is difficult to see how this secondary reaction can 
depend upon either the electromotive force or the current. Such a secondary reaction must depend only upon the presence of the reacting materials, that is, upon the presence of the reduced lead and the solution. These are always present in an accumulator and ready to produce any possible secondary reaction as soon as the charging current flows, and they remain present after the charging current stops. The evolution of hydrogen, however, does not depend upon the presence of reduced lead in the solution, but upon the current, stopping when the current stops and commencing when the current begins, although there may remain at all times an abundance of reduced lead. While it is undoubtedly true that reduced lead does act slowly on dilute sulphuric acid, evolving hydrogen and gradually discharging the charged accumulator, it is equally certain that the evolution of hydrogen at a lead cathode during electrolysis does not depend upon the presence of lead sulphate, any more than the evolution of hydrogen at a platinum cathode depends upon the presence of platinum stulphate. 